\title{
THE PREVALENCE AND RISK FACTORS OF DIABETIC MACULOPATHY IN TYPE 2 DIABETES MELLITUS: A STUDY FROM CENTRAL NEPAL
}

\author{
Nilam Munakarmi ${ }^{1}$, Amrit Pokharel ${ }^{2}$, Om Krishna Malla ${ }^{3}$, Chhabindra Lal Pradhananga ${ }^{3}$
}

\begin{abstract}
INTRODUCTION:

Diabetic maculopathy is a complication of type 2 diabetes mellitus. This study was done to assess the prevalence and risk factors of Diabetic maculopathy in type 2 diabetes mellitus in Nepalese patients presenting to our hospital.
\end{abstract}

\section{MATERIAL AND METHODS:}

A hospital-based, descriptive, cross-sectional study was conducted at the department of ophthalmology, Kathmandu Medical College Teaching Hospital (KMCTH), Sinamangal, Kathmandu, Nepal from August, 2012 to October, 2014. 200 patients with type 2 diabetes mellitus underwent a detailed interview and a comprehensive dilated ocular evaluation by an ophthalmologist. Diabetic maculopathy was defined according to the international classification and grading system.

\section{RESULTS:}

200 patients suffering from type 2 diabetes mellitus included 90 men (45\%) and 110 women (55\%) of age ranging from 2380 years (mean age $=56.23$, median age $=57.5$ and $\mathrm{SD}=10.83$ ). Diabetic maculopathy was detected in 22 patients $(11 \%)$. The disease duration of 6 to 15 years had the highest prevalence of Diabetic maculopathy. Significant risk factors for diabetic maculopathy were higher levels of HbA1c $(p=0.005)$, higher values of blood pressure $(p=0.001)$, higher cholesterol levels $(p=0.000)$, higher LDL-cholesterol levels $(p=0.000)$, higher triglyceride levels $(p=0.000)$, higher creatinine values $(p=0.000)$, higher urea values $(p=0.000)$, higher FBS levels $(p=0.020)$, higher PPBS levels $(p=$ $0.001)$ and lower hemoglobin values $(p=0.000)$.

\section{CONCLUSION:}

Significant risk factors for diabetic maculopathy were higher levels of $\mathrm{HbA1c}$, higher values of blood pressure, higher cholesterol levels, higher LDL-cholesterol levels, higher triglyceride levels, higher creatinine values, higher urea values, higher FBS levels, higher PPBS levels and lower hemoglobin values. However, smoking, drinking alcohol, dietary habits, HDL and BMI contributed as insignificant risk factors.

KEY WORDS: diabetic maculopathy, Type 2 diabetes mellitus,

1 Ophthalmologist Birat Eye Hospital, Biratnagar, Nepal

2 Optometrist, Kathmandu Medical College Teaching Hospital, Kathmandu, Nepal

3 Professor, Ophthalmologist, Kathmandu Medical College Teaching Hospital, Kathmandu, Nepal

4 Professor, Ophthalmologist, Kathmandu Medical College Teaching Hospital, Kathmandu, Nepal

\author{
For Correspondence \\ Amrit Pokhrel \\ Optometrist \\ Kathmandu Medical College, Kathmandu \\ E-mail:amritpokharel@iom.edu.np
}




\section{INTRODUCTION:}

Diabetes, as defined by the World Health Organization, is a metabolic disorder arising out of multiple etiologies and characterized by chronic hyperglycemia with disturbances of carbohydrate, fat, and protein metabolism that results from defects in insulin secretion, insulin action, or both. ${ }^{1}$ Diabetic maculopathy is the leading cause of moderate visual loss. It consists of macular edema and macular ischemia, with edema being the predominant component. Macular edema is caused by a dysfunction of the retinal vascular endothelium and/or alteration of the retinal pigment epithelium. The Wisconsin Epidemiologic Study of Diabetic Retinopathy (WESDR) group reported that the prevalence of macular edema ranged from $3 \%$ in older -onset patients, that is diabetes diagnosed at $\geq 30$ years of age with the duration of the diabetes $<5$ years to $28 \%$ in patients with a diabetes duration of $\geq 20$ years. ${ }^{2}$ The Early Treatment Diabetic Retinopathy Study (ETDRS) established that the second cause of persistent severe visual loss was macular edema. ${ }^{3}$ In patients with type 2 diabetes, however, maculopathy remains the most important cause for moderate visual loss with $29 \%$ patients developing macular edema within 20 years of diabetes. ${ }^{4}$ It has been stated that diabetic maculopathy is present in about $9 \%$ of the diabetic population.

\section{MATERIALSAND METHODS:}

The study was conducted between August, 2012 and October, 2014. Subjects who were diagnosed with type 2 diabetes mellitus and who attended the department of ophthalmology, KMCTH were recruited after ensuring they met inclusion criteria (all patients diagnosed with type 2 diabetes mellitus recent or old, attending medical and eye OPDs, with or without treatment; those patients with reports of recent blood investigations fasting blood sugar (FBS) and post-prandial blood sugar (pPBS), HbA1c, lipid profile, creatinine, urea, hemoglobin and urine albumin). Exclusion criteria were : a) Patients with reduced visual acuity due to factors other than diabetic maculopathy and diabetic retinopathy (DR) or with any ocular conditions such as glaucoma, age-related macular degeneration, corneal opacity, vitreous hemorrhage, cataract, optic atrophy, uveitis, choroiditis, retinal vasculitis and retinal diseases, b) patients with a history of previous ocular and/or laser surgery, c) those patients whose fundus could not be examined, and d) patients in whom cooperation could not be achieved with best possible efforts.

Ethical clearance approval was obtained from the Ethical Review Committee at KMCTH. Informed consent was taken from the patients before their inclusion in the study. The study variables - age, sex, BMI, the duration of diabetes mellitus, blood pressure, intraocular pressure, FBS, PPBS, HbAlc, total cholesterol, high density lipoprotein, low density lipoprotein, triglycerides, serum creatinine, serum urea, hemoglobin, urine albumin, smoking habits, drinking alcohol habits, dietary habits and physical activity were recorded on the comprehensive pro forma.
Patients enrolled in the study underwent a complete ophthalmological examination, which included visual acuity testing, slit-lamp examination, fundus biomicroscopy, Goldmann applanation tonometry, and indirect ophthalmoscopy. Only one eye of a subject was taken for analysis. In cases when both eyes had maculopathy, the findings pertaining to a worse eye were reported.

\section{STUDY PROCEDURE:}

A detailed medical history of the duration of type 2 diabetes mellitus, treatment history along with a detailed history of coexisting hypertension, smoking habits (Non-smoker, and Smoker: Ex-smoker and Current smoker), drinking alcohol habits (No: who never drinks and Yes: who drink occasionally and/or regularly), dietary habits (vegetarian and nonvegetarian), physical activity (sedentary: rarely participates in physical activity; moderate active: weekend exercise only or using feet less than half a day on weekdays; active: using feet for more than half a day on weekdays) including reports of investigation as written on the pro forma were recorded.

Diabetic maculopathy was scaled and categorized recorded following the International Clinical Classification tabulated as below:

International Clinical Diabetic Macular Edema Disease Severity Scale

\begin{tabular}{|l|l|}
\hline Proposed Disease Severity Level & Findings Observable upon dilated Ophthalmoscopy \\
\hline $\begin{array}{l}\text { Diabetic macular edema } \\
\text { apparently absent }\end{array}$ & No apparent retinal thickening or hard exudates in posterior pole \\
\hline Diabetic macular edema & Some apparent retinal thickening or hard exudates in posterior pole \\
apparently present & If diabetic macular edema is present, it can be categorized as follows: \\
\hline Proposed disease Severity Level & Findings observable upon Dilated Ophthalmoscopy \\
\hline Diabetic macular edema present & $\begin{array}{l}\text { Mild diabetic macular edema: Some retinal thickening or hard exudates in } \\
\text { posterior pole but distant from the centre of the macula }\end{array}$ \\
\cline { 2 - 3 } & $\begin{array}{l}\text { Moderate diabetic macular edema: Retinal thickening or hard } \\
\text { approaching the centre of the macula but not involving the centre }\end{array}$ \\
\cline { 2 - 3 } & $\begin{array}{l}\text { Severe diabetic macular edema: retinal thickening or hard exudates involving } \\
\text { the centre of the macula }\end{array}$ \\
\hline
\end{tabular}

Source: American Academy of Ophthalmology $2012^{6}$

Hard exudates herald current or previous macular edema. Diabetic macular edema was defined as retinal thickening detected during three-dimensional assessment best performed by dilated examination using slit-lamp biomicroscopy and/or stereoscopic fundus photography. 


\section{STATISTICALANALYSIS:}

Data were tabulated and interpreted in terms of percentage, the mean and the standard deviation using SPSS version 19 (Statistical Package for the Social Sciences). Chi-square tests and relative risks were used. A p-value of $<0.05$ was considered to be statistically significant.

\section{RESULTS:}

200 subjects (90 male and 110 female) with mean age of 56.22 years and the age range of 23 years to 80 years were enrolled. The 51-60 year age group had the greatest proportion of subjects with maculopathy. However, diabetic maculopathy was not significantly associated with age range $(p=0.965)$. Diabetic maculopathy did not correlate with age distribution $(p=0.965)$. Likewise, the results of other variables are shown in Table 1. Diabetic maculopathy was present in 22 patients (11\%) of all subjects ( 8 female and 14 male). Gender did not significantly correlate with maculopathy $(\mathrm{p}=0.063)$. Diabetic maculopathy occurred 2.35 times more often in males than in females (Odds ratio: $2.35,95 \%$ CI 0.938 5.882). Similarly odds ratios and p-values relating to other risk factors of Diabetic maculopathy are shown in Table 2. The incidence of diabetic maculopathy was highest in patients with duration of diabetes ranging from 6 to 15 years. The duration and diabetic maculopathy were positively correlated with each other $(\mathrm{p}=$ $0.000)$.

Table 1: Subjects' characteristics

\begin{tabular}{|l|l|l|l|l|}
\hline & Min - Max & Mean & Median & SD \\
\hline Age (years) & $23-80$ & 56.22 & 57.50 & 10.83 \\
\hline $\begin{array}{l}\text { Diabetes duration } \\
\text { years })\end{array}$ & $1-24$ & 7.14 & 6.00 & 5.29 \\
\hline BMI (kg/m $\left.{ }^{2}\right)$ & $14.69-47.29$ & 26.02 & 25.78 & 4.05 \\
\hline BP systolic ( mmHg) & $90-170$ & 126.45 & 130.00 & 15.85 \\
\hline BP diastolic (mm Hg) & $60-100$ & 78.25 & 80.00 & 8.99 \\
\hline FBS (mg/dl) & $40-376$ & 143.75 & 128.50 & 57.32 \\
\hline PPBS (mg/dl) & $70-400$ & 204.34 & 190.00 & 72.57 \\
\hline HbA1c (\%) & $4.88-14$ & 7.68 & 7.00 & 1.97 \\
\hline TC (mg/dl) & $89-354$ & 168.29 & 162.50 & 44.24 \\
\hline TG (mg/dl) & $59-462$ & 162.43 & 143.50 & 75.63 \\
\hline HDL (mg/dl) & $25-71$ & 43.60 & 43.00 & 7.36 \\
\hline LDL (mg/dl) & $28-210$ & 109.37 & 114.00 & 34.27 \\
\hline Urea (mg/dl) & $10-38$ & 19.45 & 19.00 & 4.33 \\
\hline Creatinine (mg/dl) & $0.40-1.90$ & 0.9309 & 0.90 & 0.22 \\
\hline Hb (g/dl) & $9-17$ & 13.00 & 13.00 & 1.74 \\
\hline
\end{tabular}

Table 2: Risk factors of Diabetic maculopathy with odds ratio

\begin{tabular}{|c|c|c|c|c|c|}
\hline $\begin{array}{l}\text { Diabetic } \\
\text { maculopathy }\end{array}$ & Frequency & $\begin{array}{l}\text { Percentage } \\
\%\end{array}$ & $\begin{array}{l}\text { Odd } \\
\text { Ratio }\end{array}$ & $\begin{array}{l}95 \% \\
\text { Confidence } \\
\text { Interval }\end{array}$ & $p$ value \\
\hline Gender & & & & \multirow{3}{*}{$0.938-5.882$} & \\
\hline Male & 14 & 64 & 2.349 & & 0.063 \\
\hline Female & 8 & 36 & 1 & & \\
\hline Smoking & & & & \multirow{3}{*}{$0.527-3.135$} & \\
\hline Yes & 10 & 45 & 1.286 & & 0.580 \\
\hline No & 12 & 55 & 1 & & \\
\hline Drinking & & & & \multirow{3}{*}{$0.418-2.530$} & \\
\hline No & 13 & 59 & 1.028 & & 0.952 \\
\hline Yes & 9 & 41 & 1 & & \\
\hline $\mathrm{BP}(\mathrm{mmHg})$ & & & & \multirow{3}{*}{$0.010-0.559$} & \multirow{3}{*}{0.001} \\
\hline Normal $(<120 / 80)$ & 1 & 4.5 & 0.073 & & \\
\hline $\begin{array}{l}\text { Abnormal }(120- \\
160 / 80-100)\end{array}$ & 21 & 95.5 & 1 & & \\
\hline FBS (mg/dl) & & & & \multirow{3}{*}{$1.149-9.192$} & \multirow{3}{*}{0.020} \\
\hline Abnormal (>126) & 17 & 77 & 3.251 & & \\
\hline Normal $(<126)$ & 5 & 23 & 1 & & \\
\hline PPBS (mg/dl) & & & & \multirow{3}{*}{$\begin{array}{l}1.920 \\
18.150\end{array}$} & \multirow{3}{*}{0.001} \\
\hline Abnormal (> 200) & 18 & 82 & 5.903 & & \\
\hline Normal $(<200)$ & 4 & 18 & 1 & & \\
\hline $\mathrm{HbA} 1 \mathrm{c}$ & & & & \multirow{3}{*}{$\begin{array}{l}1.477 \\
18.099\end{array}$} & \multirow{3}{*}{0.005} \\
\hline Abnormal $(>6.8 \%)$ & 19 & 86 & 5.170 & & \\
\hline Normal $(4-6.7 \%)$ & 3 & 14 & 1 & & \\
\hline $\begin{array}{l}\text { Total cholesterol } \\
(\mathrm{mg} / \mathrm{dl}) \\
\text { Normal }(140-199) \\
\text { High }(200-240)\end{array}$ & $\begin{array}{l}7 \\
15\end{array}$ & $\begin{array}{l}32 \\
68\end{array}$ & $\begin{array}{l}0.122 \\
1\end{array}$ & $0.047-0.322$ & 0.000 \\
\hline TG (mg/dl) & & & & \multirow{3}{*}{$0.003-0.175$} & \multirow{3}{*}{0.000} \\
\hline Normal $(<150)$ & 1 & 4.5 & 0.023 & & \\
\hline High $(>150)$ & 21 & 95.5 & 1 & & \\
\hline HDL (mg/dl) & & & & \multirow{3}{*}{$0.021-2.745$} & \multirow{3}{*}{0.213} \\
\hline Normal (Men: 35-65, & 21 & 95.5 & 0.239 & & \\
\hline $\begin{array}{l}\text { Female: } \\
35-80) \\
\text { Low }(<35)\end{array}$ & 1 & 4.5 & 1 & & \\
\hline LDL (mg/dl) & & & & \multirow{3}{*}{$0.006-0.077$} & \multirow{3}{*}{0.000} \\
\hline Normal $(<139)$ & 3 & 13 & 0.021 & & \\
\hline High $(>140)$ & 19 & 87 & 1 & & \\
\hline Urea (mg/dl) & & & & \multirow{3}{*}{$0.014-0.124$} & \multirow{3}{*}{0.000} \\
\hline Normal (8-20) & 5 & 23 & 0.041 & & \\
\hline High $(>20)$ & 17 & 77 & 1 & & \\
\hline Creatinine $(\mathrm{mg} / \mathrm{dl})$ & & & & \multirow{3}{*}{$0.058-0.487$} & \multirow{3}{*}{0.000} \\
\hline $\begin{array}{l}\text { Normal (Men: } 0.9- \\
1.3 \text {, Female: } 0.6-1.1 \text { ) }\end{array}$ & 15 & 32 & 0.169 & & \\
\hline $\begin{array}{l}\text { High } \\
\text { (Men:>1.3,Female: }> \\
1.1)\end{array}$ & 7 & 68 & 1 & & \\
\hline $\mathrm{Hb}(\mathrm{g} / \mathrm{dl})$ & & & & \multirow{3}{*}{$0.001-0.083$} & \multirow{3}{*}{0.000} \\
\hline $\begin{array}{l}\text { Normal(Male:14- } \\
\text { 17.4,Female: } 12-16 \text { ) }\end{array}$ & 1 & 4.5 & 0.011 & & \\
\hline $\begin{array}{l}\text { Low }(\text { Male: }<14, \\
\text { Female: }<12)\end{array}$ & 21 & 95.5 & 1 & & \\
\hline
\end{tabular}




\section{DISCUSSION:}

In this study, diabetic maculopathy was present in 22 patients $(11 \%)$, mild maculopathy in 6 patients $(3 \%)$, moderate in 8 patients $(4 \%)$ and severe maculopathy in 8 patients $(4 \%)$. Similar to our study was a previous study done by GolubovicArsovska $\mathrm{M}$ et al. in 2006 which reported a 10\% prevalence of diabetic maculopathy. ${ }^{7}$ Likewise another study done by AlAmer RM et al. in 2008 found that maculopathy had a prevalence of $7.8 \%{ }^{8}$ In this study Diabetic maculopathy was found more in patients with age ranged from $51-60$ years ( 9 patients , 41\%) followed by $61-70$ years ( 7 patients, $32 \%)$. It might be due to the fact that the population distribution was skewed towards older patients. The Study done by Wani J S et al. in 2003 suggest that Diabetic Maculopathy occurs more frequently in older onset diabetics. ${ }^{9}$ Diabetic maculopathy was seen more in female patients than male patients, $64 \%$ versus $36 \%$. However, there was no statistically significant difference $(p=0.063)$ in the prevalence of diabetic maculopathy and gender distribution. In our study maximum patients attending were the ones with a history of diabetes mellitus for 1-5 years, which was followed by the disease duration of 6-10 years followed by 11-25 years. Maximum patients attending were the ones with history of Diabetes Mellitus less than 10 years in a study conducted by Shrestha et al. in $2007 .^{10}$

The greatest proportion of patients with diabetic maculopathy had the disease duration of 6 to 15 years. Mociran $M$ et al. in 2009 found that the prevalence of Diabetic maculopathy was greatest in those with duration of diabetes of $>5$ years. Diabetic Maculopathy was present in 11 patients $(6.43 \%)$ taking OHA and 11 patients (52.38\%) under insulin therapy. The highest risk for the development of Diabetic Maculopathy and DR was in those patients having Diabetes Mellitus for more than 5 years, regardless of whether the patients were on insulin therapy or on oral treatment as concluded by the study done by El Haddad et al. in $1998 .^{12}$

The prevalence of diabetic maculopathy was greatest in patients with stage 1 hypertension in 16 patients $(73 \%)$. Normal BP was negatively associated with diabetic maculopathy (Odds ratio: 0.073 with 95\% CI 0.0100 .559 ) which was statistically significant $(\mathrm{p}=0.001)$. This suggests fewer chances of Diabetic maculopathy in patients with normal BP. High blood pressure was significantly associated with prevalence of Diabetic maculopathy $(p=0.001)$. The United Kingdom Prospective Diabetes Study reported that the occurrence of retinopathy was associated with higher systolic blood pressure $(p=0.01)$. High blood pressure has a higher risk of developing macular edema according to the study done by Lopes de Faria el al. ${ }^{13}$ Diabetic patients with concomitant hypertension are reportedly three times more likely develop diffuse diabetic maculopathy. ${ }^{14}$

In our study smoking was not significantly associated with Diabetic maculopathy $(\mathrm{p}=0.580)$. Diabetic maculopathy was not observed in patients who were active, but observed more frequently in patients with moderately active and sedentary lifestyles and also seen more in patients who were nonvegetarian by diet. In much the same way, diabetic maculopathy was not significantly associated with consumption of alcohol $(p=0.952)$ and BMI $(p=0.451)$. The study conducted by Mociran. M et al. in 2009 found diabetic maculopathy was not associated with BMI $(\mathrm{p}=0.301)^{11}$ Likewise WESDR III found that there was no association between the presence of DR and BMI. ${ }^{15}$ It is due to the fact that some people might get thinner after diabetes so BMI after diabetes might have no effect while before might have some effects.

A greater proportion of subjects with diabetic maculopathy (19 patients, $86 \%$ ) had $\mathrm{HbA} 1 \mathrm{c}>6.7 \%$, whereas in patients with $\mathrm{HbA} 1 \mathrm{c}<6.7 \%$ diabetic maculopathy was present in only 3 patients $(14 \%)$. Various studies showed that glycated hemoglobin is the only indicator that is very sensitive. In this regard, we can recommend that glycated hemoglobin needs to be considered as a risk factor which helps predict who will develop diabetic maculopathy in a group of DR. This study showed significant association between FBS and PPBS with diabetic maculopathy with a p-value between 0.020 and 0.001 . The study done by Jew OM et al. in 2012 found FBS in the clinically diabetic maculopathy group was significantly higher $(\mathrm{p}<0.001)$ compared to the non- diabetic maculopathy group.

The association between serum lipids and diabetic maculopathy is biologically plausible. There is direct involvement of serum lipids in endothelium dysfunction which subsequently results in the breakdown of the blood retinal barrier leading to exudation of serum lipids and lipoproteins to intercellular space in the retina. ${ }^{17}$ Diabetic maculopathy associated with total cholesterol $(\mathrm{p}=0.000)$, triglyceride $(p=0.000), \operatorname{LDL}(p=0.000)$ and $\operatorname{HDL}(p=0.213)$. The study conducted by Mociran M et al. in 2009 found similar results that diabetic maculopathy associated with total cholesterol $(\mathrm{p}=0.008)$, triglyceride $(\mathrm{p}=0.050)$, HDL $(\mathrm{p}=$ $0.709){ }^{11}$

Likewise, in a study done by Jew OM et al. in 2012 showed serum cholesterol in the diabetic maculopathy group was significantly higher compared to the non-diabetic maculopathy group, serum LDL in the diabetic maculopathy group was also significantly higher than the non-diabetic maculopathy group. ${ }^{16}$ Serum cholesterol $(p=0.023)$, serum LDL cholesterol $(\mathrm{p}=0.001)$ and non-HDL-cholesterol $(\mathrm{p}=$ $0.015)$ concentrations were significantly higher in the retinopathy subjects with diabetic maculopathy compared with those without diabetic maculopathy. ${ }^{18}$ Different studies including this study showed that a high level of total cholesterol, LDL, and triglyceride were all sensitive indicators of diabetic maculopathy in DR.

Diabetic maculopathy was associated with elevated serum creatinine $(p=0.000)$ and urea $(p=0.000)$. These results are supported by the study done by Zander .E et al. in 2000 that 
concluded diabetic maculopathy was associated with elevated serum creatinine levels $(\mathrm{p}<0.05) .{ }^{19}$ The study done by Jew $\mathrm{OM}$ et al. in 2012 concluded that serum urea and creatinine level, which reflects the renal function, were significantly higher in the diabetic maculopathy group. ${ }^{16}$ The hemoglobin level was lower in diabetic maculopathy patients. This study showed there was association between low hemoglobin with diabetic maculopathy $(\mathrm{p}=0.000)$. This results was supported by the study done by Jew OM et al. in 2012 which concluded that the hemoglobin level was lower $(\mathrm{p}=0.004)$ in the diabetic maculopathy group as compared to the non-diabetic maculopathy group. ${ }^{16}$ So these studies help us to find that a low level of hemoglobin is also a sensitive indicator of diabetic maculopathy in DR. This study showed that reduced visual acuity was only associated in those with moderate to severe disease. Study conducted by Davis MD et al. in 1998 concluded that baseline visual acuity to be an important risk factor for the development of severe degrees of visual loss. ${ }^{15}$

From this study, we found that poor glycaemic control, higher baseline total cholesterol, LDL cholesterol and triglycerides were the most important risk factors in the development and progression of diabetic maculopathy. Thus, the results further underline the fact that intensive treatment of hyperglycaemia from its early phases among patients with type 2 diabetes will at least delay the development of diabetic maculopathy and associated impairment of visual acuity. $\mathrm{HbA} 1 \mathrm{c}$ has been shown to be a significant risk factor for diabetic macular edema in this study. Another issue is the association between $\mathrm{HbA} 1 \mathrm{c}$ and lipid profiles which had been evaluated in a few studies. It was shown that both HbAlc and FBS had direct correlations with cholesterol,

TG and LDL and inverse correlation with HDL, the magnitude of correlation being higher for HbAlc. FBS, longer duration of diabetes, as well as low hemoglobin was found to be the risk factors for developing diabetic maculopathy. Serum urea and creatinine level, which reflects the renal function, were significantly higher in diabetic maculopathy. In conclusion, high cholesterol and high HbAlc levels were the two most important risk factors that led to the development of diabetic maculopathy in this study. This result was consistent with most previous studies underlining the need for better glycaemic and lipid control in the prevention of diabetic macular edema. We advocate strict glycemic and lipid control among diabetic patients especially those who are on the way to developing maculopathy. Correction of those above risk factors may reduce macular edema and should be included as part of the total management of patients with Diabetic maculopathy.

Thereby, good glycemic control and the treatment of potential systemic diseases such as hypertension and renal failure are recommended. Lipid-lowering therapy may be useful as an adjunct in the management of DR. However, there have been no large randomized clinical trials that have shown efficacy of lipid-lowering therapy in reducing the risk of macular edema or progression of retinopathy. Intensive blood glucose control and control of systemic hypertension reduce the risk of new onset DR and slow the progression of existing DR.

\section{CONCLUSION:}

Significant risk factors for Diabetic maculopathy were higher levels of HbA1c, higher values of blood pressure, higher cholesterol levels, higher LDL-cholesterol levels, higher triglyceride levels, higher creatinine values, higher urea values, higher FBS levels, higher PPBS levels and lower hemoglobin values.

\section{REFERENCES:}

1. Badran M, Laher I. Type II diabetes mellitus in Arabic-speaking countries. International journal of endocrinology 2012;2012.

2. Yamamoto T, Iimuro S, Ohashi $Y$, Sone H, Yamashita H, Ito H. Prevalence and risk factors for diabetic maculopathy, and its relationship to diabetic retinopathy in elderly Japanese patients with type 2 diabetes mellitus. Geriatrics \& gerontology international 2012;12:134-140.

3. Fong DS, Ferris FL, Davis MD, Chew EY, Early Treatment Diabetic Retinopathy Study Research G. Causes of severe visual loss in the early treatment diabetic retinopathy study: ETDRS report no. 24. American journal of ophthalmology 1999;127:137-141.

4. Negi AK, Vernon SA, Lim CS, Owen-Armstrong K. Intravitreal triamcinolone improves vision in eyes with chronic diabetic macular oedema refractory to laser photocoagulation. Eye 2005; 19:747-751.

5. Casswell AG, Canning CR, Gregor ZJ. Treatment of diffuse diabetic macular oedema: a comparison between argon and krypton lasers. Eye 1990;4:668-672.

6. American Academy of Ophthalmology. Clinical statement. International clinical classification system for DR and Diabetic Macular edema. San Francisco, CA: American Academy of Ophthalmology; 2012.

7. Golubovic-Arsovska M. Correlation of diabetic maculopathy and level of diabetic retinopathy. Prilozi / Makedonska akademija na naukite $i$ umetnostite, Oddelenie za bioloski $i$ medicinski nauki = Contributions / Macedonian Academy of Sciences and Arts, Section of Biological and Medical Sciences 2006;27:139-150.

8. Al-Amer R, Khader Y, Malas S, Abu-Yaghi N. Prevalence and Risk Factors of Diabetic Retinopathy among Jordanian Patients with Type 2 Diabetes. Digital Journal of Ophthalmology 2008;14.9. Male Ft. Incidence Of Maculopathy In Nonproliferative And Proliferative Diabetic Retinopathy. JkPractitioner 2003;10:275-278.

10. Shrestha S, Malla OK, Karki DB, Byanju RN. Retinopathy in a diabetic population. 2007. 
11. Mociran M, DragoS C, Hâncu N. Risk Factors and Severity of Diabetic Retinopathy in Maramureş. Applied Medical Informatics 2009;24:47-52.

12. El Haddad OAW, Saad MK. Prevalence and risk factors for diabetic retinopathy among Omani diabetics. British journal of ophthalmology 1998;82:901-906.

13. Lopes de Faria JM, Jalkh AE, Trempe CL, McMeel JW. Diabetic macular edema, Risk factors and concomitants. Acta ophthalmologica Scandinavica 1999;77:170-175.

14. Aiello LP, Cahill MT, Wong JS. Systemic considerations in the management of diabetic retinopathy. American journal of ophthalmology 2001;132:760-776.

15. Davis MD, Fisher MR, Gangnon RE, et al. Risk factors for highrisk proliferative diabetic retinopathy and severe visual loss: Early Treatment Diabetic Retinopathy Study Report \#18. Investigative Ophthalmology \& Visual Science 1998;39: 233-252.
16. Jew OM, Peyman M, Chen TC, Visvaraja S. Risk factors for clinically significant macular edema in a multi-ethnics population with type 2 diabetes. International journal of ophthalmology 2012;5:499.

17. Benarous R, Sasongko MB, Qureshi S, et al. Differential association of serum lipids with diabetic retinopathy and diabetic macular edema. Investigative ophthalmology \& visual science 2011;52:7464-7469.

18. Rema M, Srivastava BK, Anitha B, Deepa R, Mohan V. Association of serum lipids with diabetic retinopathy in urban South Indiansthe Chennai Urban Rural Epidemiology Study (CURES) Eye Study2. Diabetic medicine 2006;23:1029-1036.

19. Zander E, Herfurth S, Bohl B, et al. Maculopathy in patients with diabetes mellitus type 1 and type 2: associations with risk factors. British journal of ophthalmology 2000;84:871-876. 